\title{
Character Education in Local Wisdom-Based Schools
}

\section{Felta}

\author{
Program Studi Sastra Indonesia \\ Fakultas Ilmu Budaya, Universita Halu Oleo
}

\begin{abstract}
Abstrak
Education is an important pillar in the development of children's cognition. Since the beginning of human civilization, it was there that education emerged. Education is a series of ways of acquiring knowledge and self-perfection by humans continuously or continuously. Humans are not free from limitations and shortcomings so that to complement these limitations and shortcomings, humans must process, one of which is through the acquisition of knowledge through education. Education obtained by humans is not only through formal education but early education obtained by humans is through the family environment and the community environment.
\end{abstract}

Keyword: chracter, education, local wisdom, based schools 


\section{Pendahuluan}

Pembangunan nasional dalam segala bidang yang telah dilaksanakan selama ini mengalami berbagai kemajuan. Namun, ditengah-tengah kemajuan tersebut terdapat dampak negatif, yakni terjadinya pergeseran nilai-nilai etika dalam kehidupan berbangsa dan bernegara. Pergeseran sistem ini Nampak dalam kehidupan masyarakat dewasa ini, seperti penghargaan terhadap nilai budaya dan bahasa, nilai solidaritas sosial, musyawarah mufakat, kekeluargaan, sopan santun, kejujuran, rasa malu, dan rasa cinta tanah air semakin memudar. pesan-pesan kontribusi, serta sarana dalam membangun watak bangsa (Nation and Character).

Hal tersebut dapat dibuktikan dengan peran perjuangan para pahlawan pendidikan, seperti Ki Hajar Dewantara, Cipto Mangunkusumo, dan Douwes Dekker yang mampu merintis pembangunan pendidikan bangsa Indonesia dengan mendirikan Taman Siswa pada Tahun 1922, dan secara bertahap meningkatkan pemahaman , kesadaran, serta kecerdasan masyarakat Indonesia, yang tertuang pada Undang-Undang Republik Indonesia Nomor 20 Tahun 2003 tentang Sistem Pendidikan Nasional yaitu: mengembangkan potensi peserta didik agar menjadi manusia yang beriman, dan bertakwa kepada Tuhan Yang Maha Esa, berakhlak mulia, sehat, berilmu, cakap, kreatif, mandiri, dan menjadi warga Negara yang demogratis serta bertanggung jawab (Aqib, 2011). Ini semua Dalam rangka mencerdaskan kehidupan bangsa. Sebuah harapan besar sangat tampak dan terlihat bagi Pendidikan Indonesia dapat mencapai cita-cita tersebut. Terlebih jika dikaitkan bahwa pendidikan mempunyai peranan yang sangat strategis dalam pembangunan suatu bangsa.

Adanya tujuan pendidikan nasional juga diharapkan mampu menjadi satu fokus utama dalam menciptakan pembelajaran yang berorientasi akhlak dan moralitas serta pendidikan agama dapat terealisasikan dalam kehidupan sehari-hari. Harapannya, lulusan pendidikan memiliki kepekaan untuk membangun silaturrahmi, toleransi, dan kebersamaan dalam kehidupan masyarakat yang majemuk. Selain itu juga, pendidikan Indonesia menemukan kembali ideologi pendidikan yang sempat hilang dan tidak terarah, yakni pendidikan demogratis bermoral pancasila sesuai dengan pernyataan pencetus pendidikan karakter yaitu pedagogik Jerman FW Foerster tahun 1869-1966 yang dikutip oleh Elmubarok tahun 2008 pada halaman 104 yang menekankan dimensi etis-spiritual dalam proses pembentukan pribadi. Pendidikan karakter itu sendiri merupakan sebuah usaha untuk menghidupkan kembali pedagogki ideal-spiritual yang sempat hilang (Masruroh, 2011).

Oleh karena itu para ahli dan praktisi dalam pendidikan semakin menyadari betapa pentingnya peranan pendidikan afektif dalam pencapaian tujuan pendidikan yang sebenarnya. Tujuan tersebut ialah bahwa peserta didik mampu dan mau mengamalkan pengetahuan yang diperoleh dari dunia pendidikan dalam kehidupan sehari-hari. Terlebih setelah muncul suatu penemuan bahwa EQ (Emotional quotient) menyambung $80 \%$ terhadap keberhasilan seseorang dalam kehidupan, dibandingkan dengan IQ yang hanya menyambung 20\%. Sehingga menguatkan bahwa "keseimbangan antara zikir (menyadari kekuasaan Allah) dan pikir (mengingat, memahami, menerapkan, menganalisis, menyintesis dan mengevaluasi) merupakan ajaran Islam yang 
kebenarannya telah terbukti secara empiris, yakni terbentuknya akhlak mulia dan kecerdasan secara terpadu" (Aqib, 2011).

Dunia intersubjektif ikut andil dalam menentukan kehidupan anak-anak remaja dalam lingkungan masyarakat. Artinya, tabiat, sifat, dan perilaku anak-anak remaja dipengaruhi oleh budaya dalam lingkungannya. Budaya tersebut termanifestasi dalam mengelola dan memengaruhi pembawaan sifat dan perilaku para remaja. Hal ini sejalan dengan pendapat Ritzer (dalam Susiati, et.al, 2021), dunia intersubjektif menciptakan suatu realitas sosial yang dipaksa oleh struktur budaya dan lingkungan sosial ciptaan leluhur mereka sebelumnya (hal. 35)

Oleh karena itu, pada diri remaja diperlukan sosialisasi dan internalisasi nilai-nilai semenjak mereka masih kecil. Ritzer (2014) mengatakan bahwa syarat dan fungsi bagi terpeliharanya integritas pola nilai di dalam sistem adalah proses internalisasi dan sosialisasi (hal. 86). Susiati (2019) mengatakan bahwa manusia adalah makhluk sosial yang perkembangan jiwanya tidak ditentukan sejak lahir tetapi dibentuk oleh lingkungannya. Lingkungan manusia itulah yang disebut kebudayaan (hal. 117).

Pendidikan merupakan pilar penting dalam perkembangan kognisi anak. Sejak dimulainya peradaban manusia disitu pulalah pendidikan muncul. Pendidikan adalah suatu runtunan dalam cara pemerolehan ilmu dan penyempurnaan diri yang dilakukan manusia secara terus menerus atau berkelanjutan. Manusia tidak luput dari keterbatasan dan kekurangan sehingga untuk melengkapi keterbatasan dan kekurangan yang dimiliki tersebut, manusia harus berproses, salah satunya melalui pemerolehan ilmu melalui pendidikan. Pendidikan yang diperoleh oleh manusia tidak hanya melalui pendidikan formal tetapi pendidikan awal yang didapatkan oleh manusia adalah melalui lingkungan keluarga dan lingkungan masyarakat (Tuasalamony et.al, 2020).

Peranan orang tua dalam membentuk suatu karakter anak sangatlah penting sebab pertama kali anak menerima sosialisasi dari lembaga keluarga. orang tua merupakan cerminan dari anak sehingga anak akan menjadi apa nantinya bergantung dari cara didikan orang tua terutama karakter khususnya dalam sikap religiusitas anak dalam bermasyarakat. Pendidikan beragama juga sangat penting diberikan kepada anak karena hal tersebut dapat menjadi bekal seorang anak dalam kehidupan bermasyarakat kelak.

Peran orang tua dalam memberikan pendidikan religiusitas kepada anak sangat terlihat. Pendidikan religiusitas sangat penting bagi mereka untuk didapatkan oleh anak pada usia dini. Bagi para orang tua, dengan pendidikan agama yang diberikan kepada anak, dapat memberikan pemahaman tentang baik buruk dalam masyarakat sehingga anak-anak tersebut kelak tidak terjerumus dalam hal-hal yang bersifat negatif (Buton, et.al, 2020).

Setiap anak lahir dengan temperamen, kebutuhan, dan bakatnya masing-masing. Tidak ada yang salah dengan segala perbedaan tersebut karena sejatinya setiap anak 
mempunyai potensi untuk mengembangkan karakter yang baik dan menjadi kontribusi positif untuk masyarakat, kelak setelah dia dewasa (Priyatna, 2011). Kepedulian terhadap pengembangan aspek afektif banyak yang difokuskan pada segi evaluasi, termasuk perumusan tujuan instruksional. Pada akhir-akhir ini, khususnya di Indonesia, ba-nyak yang tertarik pada prosesnya, yakni proses pengembangan ketrampilan afektif. Ketrampilan afektif disini dimaksudkan meliputi ketrampilan intra pribadi yang berkaitan dengan kemampuan mengola diri sendiri dan ketrampilan antarpribadi yang berhubungan dengan pengembangan kemampuan mengadakan hubungan antarpribadi antar sesama manusia yang lain. Kepedulian tersebut dilandasi sebuah kesadaran bahwa tanpa adanya keterpaduan antara aspek afektif dan kognitif, perasaan dan pikiran, atau dzikir dan pikir, tidak akan dapat dihasilkan sumber daya manusia yang berilmu amaliah dan beramal ilmiah. Hal itu juga telah menjadi salah satu alasan penerapan pendidikan karakter di beberapa sekolah yang sudah menerapkannya dan juga menjadi salah satu pusat perhatian oleh pemerintah dalam pencapaian pendidikan Nasional (Aqib, 2011).

Dahulu masyarakat tidak mengutamakan pendidikan karena masyarakat menganggap bahwa berpendidikan tinggi sangat menguras harta. Selain itu, dulu banyak para remaja yang tidak melanjutkan sekolah di perguruan tinggi karena belum adanya Universitas di Kabupaten Buru. Padahal dengan mengenyam pendidikan sampai ke perguruan tinggi, jika selesai akan mengubah aspek kehidupan baik kepada diri sendiri maupun ketika berada di masyarakat (Hatuwe et.al, 2021). Modernisasi mengikis budaya lokal menjadi kebarat-baratan, sedangkan puritanisme sering menganggap budaya sebagai praktik sinkretis yang harus dihindari.

Pendidikan karakter bangsa ini urgen dan diajarkan dan dijadikan teladan. Murid atau peserta didik tidak hanya harus dicerdaskan secara intelektual dan emosional, namun juga karakternya perlu dibangun agar nantinya tercipta pribadi yang unggul dan berakhlak mulia.

Pendidikan sangatlah penting, maka dari itu pemerintah mewajibkan belajar 9 tahun. Dalam pelaksanaan pendidikan, salah satunya pendidikan karakter, pihak Kementerian Pendidikan dan Kebudayaan (KEMENDIKBUD) mencantumkan pendidikan karakter yang bisa membangun bangsa untuk masa depan Indonesia (Sofan, 2011). Tujuan pendidikan karakter adalah sebagai peningkatan wawasan, perilaku, dan ketrampilan, dengan berdasarkan 4 pilar pendidikan. Tujuan akhirnya adalah terwujudnya insan yang berilmu dan berkarakter. Namun, pendidikan karakter belum menunjukkan hasil yang mengembirakan. Hal tersebut diantaranya disebabkan oleh pemahaman orang tua yang masih minim, lingkungan anak didik yang tidak kondusif bagi tumbuh kembang emosi dari psikologisnya, dan situasi negara yang menumbuhsuburkan jiwa korupsi. 
Dekadensi moral anak bangsa semakin memprihatinkan. Karakter telah pertaruhkan dalam tempat yang tidak semestinya. Jika tidak hati-hati, bangsa ini menuju pada apa yang dinamakan The Lost Generation. Semua patut bersyukur banyak pihak yang menyadari kondisi tersebut. Kesadaran itu membawa diskursus dalam banyak kesempatan dan muaranya adalah revitalisasi character building. Meskipun diskursus pendidikan karakter marak dibicarakan, ada yang pro dan ada yang kontra, hal ini wajar dalam dinamika kehidupan nalar masyarakat, dan itu menandakan adanya kehidupan berpikir, dengan kata lain diskursus pendidikan karakter telah masuk dalam pikiran masyarakat (Barnawi, 2012).

Stakeholder pendidikan semakin menyadari betapa pentingnya pembangunan karakter anak bangsa sejalan dengan pembangunan kapasitas intelektualnya. Keduanya merupakan satu kesa-tuan, tanpa karakter adanya pengetahuan tidak berdampak pada kemaslahatan, begitu juga sebaliknya. Melalui pendidikan karakter inilah, para peserta didik lebih berpeluang memiliki perilaku yang bertanggungjawab sebagai generasi penerus bangsa. Dengan perilaku demikian, kondisi berbangsa dan bernegara akan menjadi lebih baik. Dengan karakter itu pula ketentraman masyarakat dapat terjaga lebih baik, karena hubungan antara individu terjalin baik. Kejujuran, sportivitas, dan semangat belajar/kerja menjadi dari karakter positif yang telah lama coba tegakkan. Sayangnya, tidak semua anak bangsa berperilaku positif seperti yang harapkan dalam kehidupan sehari-hari (Aqib, 2011).

Tampaknya masyarakat Indonesia belum dapat berlapang dada karena pada kenyataannya pendidikan di Indonesia masih dihadapkan pada masalah pokok sistem pendidikan nasional, salah satunya menurutnya akhlak dan moral peserta didik dan manajemen pendidikan yang tidak sejalan dengan pembangunan nasional, serta sumber daya manusia yang kurang professional.

Hal ini dapat dilihat dari kenyataan tentang keadaan masyarakat yang dilihat secara umum yaitu: pertama, kondisi masyarakat yang telah hilang identitas, nilai-nilai spiritual serta terasa terasing dari diri, lingkungan dan nilai-nilai moral yang dianutnya, disebabkan karena terhimpit dengan percepatan arus informasi dan globalisasi; Kedua, banyaknya program televisi dan $\mathrm{CD}$ yang diperuntukan untuk anak didik yang tidak sesuai dengan usia peserta didik; Ketiga, tidak sedikit tayangan yang bertentangan dengan ajaran agama bahkan mengajarkan kepada para remaja tentang gaya pergaulan bebas dan mengeksplorkan gaya berpacaran di usia remaja; Keempat, berlangsungnya pendidikan yang kurang bermakna bagi pengembangan pribadi dan watak peserta didik, yang berakibat menurunnya moralitas dan kesadaran makna hakiki kehidupan, misalnya banyak tayangan televisi yang mempertontonkan sikap dan moral siswa yang kurang baik terhadap sesama atau kepada orang yang lebih tua (orang tua, guru); Kelima, hilangnya rasa solidaritas kepada sesame, sehingga harapan yang diinginkan para pendidik tidak dapat terealisasikan de-ngan baik dan efektif.

Perhatian pemerintah sangat besar terhadap pengembangan budaya dan karakter bangsa di negeri ini. Bahkan kini menjadi program unggulan pemerintah. Sampai-sampai melibatkan 16 kementerian. Ini memberikan gambaran betapa seriusnya pengembangan pendidikan karakter dan budaya bangsa di negara ini (Sulhan, 2011). 
Kearifan lokal merupakan bagian dari konstruksi budaya. Kearifan lokal mengacu pada berbagai kekayaan budaya yang tumbuh dan berkembang dalam sebuah masyarakat yang dikenal, dipercayai dan diakui sebagai elemen-elemen penting yang mampu mempertebal kohesi sosial di antara warga masyarakat. Kearifan lokal secara dominan masih diwarnai nilai-nilai adat seperti bagaimana suatu kelompok sosial melakukan prinsip-prinsip konservasi, manajemen dan eksploitasi sumber daya alam. Perwujudan bentuk kearifan lokal yang merupakan pencerminan dari sistem pengetahuan yang bersumber pada nilai budaya di berbagai daerah di Indonesia, memang sudah banyak yang hilang dari ingatan komunitasnya. Namun, di sebagian kalangan komunitas itu walaupun sudah tidak lengkap lagi atau telah berakulturasi dengan perubahan baru dari luar, masih tampak ciri-ciri khasnya dan masih berfungsi sebagai pedoman hidup masyarakat.

Eksplorasi terhadap kekayaan luhur budaya bangsa, sangat perlu untuk dilakukan, sekaligus yang berupaya untuk mengkritisi eksistensinya terkait dengan keniscayaan adanya perubahan budaya. ruang eksplorasi dan pengkajian kearifan lokal menjadi tuntunan tersendiri bagi eksplorasi khasanah budaya bangsa pada umumnya. Keunggulan lokal merupakan segala sesuatu yang merupakan ciri khas kedaerahan yang mencakup aspek ekonomi, budaya, komunikasi, ekologi, agama, dan lain-lain. Beberapa para ahli mengatakan bahwa keunggulan lokal adalah hasil bumi, kreasi seni, tradisi, budaya, pelayanan, jasa, sumber daya alam, sumber daya manusia atau lainnya yang menjadi keunggulan suatu daerah (Ahmadi, 2012).

Harapannya,dengan memperhatikan kebijakan pendidikan karakter disekolah serta bagaimana pelaksanaan pembiasaannya terhadap peserta didik, mampu memberikan kontribusi terhadap bangsa dalam pengembangan kepribadian siswa sebagai bentuk pencapaian tujuan Pendidian Nasional. Tujuannya untuk mengembangkan potensi peserta didik agar menjadi manusia yang beriman, dan bertaqwa kepada Tuhan Yang Maha Esa, berakhlak mulia, sehat, cakap, kreatif, mandiri, dan menjadi warga Negara yang demogratis serta bertanggung jawab dalam rangka mencerdaskan kehidupan bangsa serta mampu mengembalikan identitas diri bangsa Indonesia yakni sistem pendidikan Pancasila.

\section{Sumber}

Aqib, Z. (2011). Panduan \& alikasi pendidikan karakter untuk: SD/MI, SMP/MTs, SMA/MA, SMK/MAK. Ban-dung: Yrama Widya.

Aqib, Z. (2010). Pendidikan karakter membangun perilaku positif anak bangsa. Bandung: Yrama Widya.

Priyatna, A. (2011). Parenting for character building panduan bagi orang tua untuk membangun karakter anak sejak dini. Jakarta: PT Alex Media Komputindo Kelompok Gramedia.

Barnawi et al. (2012). Strategi \& kebijakan pembelajaran pendidikan karakter. Yogyakarta: Ar-Ruzz Media. 
Sulhan, N. (2011). Panduan praktis pengembangan karakter dan budaya bangsa sinergi sekolah dengan rumah. Surabaya: JP Press Media Utama (Jawa Pos Grup).

Ahmad, L. K. (2011). Mengembangkan pendidikan berbasis keunggulan lokal dalam KTSP. Jakarta: Prestasi Pustakaraya.

Sartini. (2004). Menggali kearifan lokal nusantara sebuah kajian filsafat. Jurnal Filsafat (Jilid. 37, No. 2).

Zuriah, N. (2011). Model pengembangan pendidikan kewarganegaraan multikultural berbasis kearifan lokal" (studi di perguruan tinggi Kota Malang. Disertasi S-3 Program Studi Doktor Ilmu Pendidikan dalam Bidang Pendidikan Kewarganegaraan tidak dipublikasikan: Universitas Pendidikan Indonesia Bandung.

Ridwan, N. A. (2007). Landasan Keilmuan Lokal. Jurnal IBDA, 5 (1), 2-3.

Iye, R., \& Susiati, S. (2018). NILAI EDUKATIF DALAM NOVEL SEBAIT CINTA DI BAWAH LANGIT KAIRO KARYA MAHMUD JAUHARI ALI (Educative Values in Sebait Cinta di Bawah Langit Kairo by Mahmud Jauhari Ali). Sirok Bastra, 6(2), 185191.

Ritzer, G. (2014). Teori Sosiologi Modern. Terjemahan. Jakarta: Kencana Prenadamedia Group.

Susiati, S., Masniati, A., Tuasalamony, K., Hatuwe, R. S. M., Tahir, S. Z. B., Tenriawali, A. Y., \& Marasabessy, R. N. (2020). MEMBANGUN KETAHANAN RELEGIUS ANAK MELALUI ACTIVE PARENTAL INVOLVEMENT. Jurnal Islam Nusantara, 4(1), 111125.

Susiati, \& Taufik. (2019). Nilai Pembentuk Karakter Masyarakat Wakatobi Melalui Kabhanti Wa Leja. Jurnal Totobuang, 7(1), 117-137.

Susiati, S., Iye, R., \& Suherman, L. O. A. (2019). Hot Potatoes Multimedia Applications in Evaluation of Indonesian Learning In SMP Students in Buru District. ELS Journal on Interdisciplinary Studies in Humanities, 2(4), 556-570.

Susiati, S., Masniati, A., \& Iye, R. (2021). Kearifan Lokal Dalam Perilaku Sosial Remaja Di Desa Waimiting Kabupaten Buru. Sang Pencerah: Jurnal Ilmiah Universitas Muhammadiyah Buton, 7(1), 8-23.

Susiati, S., Tenriawali, A. Y., Nursin, N., Nacikit, J., \& Mukadar, S. (2020). NILAI EDUKASI DALAM NOVEL PARTIKEL KARYA DEWI LESTARI:(The Value of Education in Particle Novels by Dewi Lestari). Uniqbu Journal of Social Sciences, 1(3), 176-183.

Susiati, S. (2020). Nilai Budaya Suku Bajo Sampela Dalam Film The Mirror Never Lies Karya Kamila Andini.

Susiati, S., Tenriawali, A. Y., Nursin, N., Nacikit, J., \& Mukadar, S. (2020). NILAI EDUKASI DALAM NOVEL PARTIKEL KARYA DEWI LESTARI:(The Value of Education in Particle Novels by Dewi Lestari). Uniqbu Journal of Social Sciences, 1(3), 176-183.

Tuasalamony, K., Hatuwe, R. S. M., Susiati, S., Masniati, A., \& Marasabessy, R. N. (2020). PENGEMBANGAN PENDIDIKAN KARAKTER DI SEKOLAH DASAR NEGERI 5 NAMLEA. Pedagogy, 7(2), 81-91. 
Hatuwe, Rahma Satya Masna., Tuasalamony, Kurniati., Susiati, Susiati, Masniati, Andi., dan Yusuf, Salma. (2021). MODERNISASI TERHADAP PERUBAHAN SOSIAL MASYARAKAT DESA NAMLEA KABUPATEN BURU. Nusantara: Jurnal Ilmu Pengetahuan Sosial, 8(1), 84-96

Susiati, S. PERWUJUDAN SIMILE OLEH MERARI SIREGAR DALAM NOVEL AZAB DAN SENGSARA.

Susiati, S. NILAI BUDAYA SUKU BAJO SAMPELA DALAM FILM THE MIRROR NEVER LIES KARYA KAMILA ANDINI.

Susiati, S. (2020). Emosi Verbal Suku Bajo Sampela.

La Djamudi, N., \& Nazar, A. (2020, May). Wolio's Oral Literary Form the Character of Millennial in Buton Islands. In 1st Borobudur International Symposium on Humanities, Economics and Social Sciences (BIS-HESS 2019) (pp. 132-135). Atlantis Press.

Susiati, S. (2020). Nilai Pembentuk Karakter Masyarakat Wakatobi Melalui Kabhanti Wa Leja. 